\title{
Article \\ Fatty Acid Profile, Lipid Quality and Squalene Content of Teff (Eragrostis teff (Zucc.) Trotter) and Amaranth (Amaranthus caudatus L.) Varieties from Ethiopia
}

\author{
Endale Amare ${ }^{1,2, *}$, Luca Grigoletto ${ }^{2}$, Viviana Corich ${ }^{2}$, Alessio Giacomini ${ }^{2}$ (D) and Anna Lante ${ }^{2, *(D)}$ \\ 1 Food Science and Nutrition Research Directorate, Ethiopian Public Health Institute, P.O. Box 1242, \\ 1000 Addis Ababa, Ethiopia \\ 2 Department of Agronomy, Food, Natural Resources, Animals and Environment, University of Padova, \\ 35122 Padova, Italy; luca.grigoletto@unipd.it (L.G.); viviana.corich@unipd.it (V.C.); \\ alessio.giacomini@unipd.it (A.G.) \\ * Correspondence: enda197@gmail.com (E.A.); anna.lante@unipd.it (A.L.); Tel.: +251-911-743935 (E.A.); \\ +39-0498272920 (A.L.); Fax: +251-11-2758634 (E.A.); +39-0498272929 (A.L.)
}

\section{check for}

updates

Citation: Amare, E.; Grigoletto, L.; Corich, V.; Giacomini, A.; Lante, A. Fatty Acid Profile, Lipid Quality and Squalene Content of Teff (Eragrostis teff (Zucc.) Trotter) and Amaranth (Amaranthus caudatus L.) Varieties from Ethiopia. Appl. Sci. 2021, 11, 3590. https://doi.org/10.3390/ app11083590

Academic Editor: José Manuel Moreno-Rojas

Received: 12 March 2021

Accepted: 13 April 2021

Published: 16 April 2021

Publisher's Note: MDPI stays neutral with regard to jurisdictional claims in published maps and institutional affiliations.

Copyright: (c) 2021 by the authors. Licensee MDPI, Basel, Switzerland. This article is an open access article distributed under the terms and conditions of the Creative Commons Attribution (CC BY) license (https:/ / creativecommons.org/licenses/by/ $4.0 /)$.
Abstract: Teff and amaranth are gluten-free cereals with significant nutritional and health benefits. However, they are underutilized and known in limited areas of the world. The present study evaluated the fatty acid profile, crude fat, squalene content and lipid quality of seven teff (Eragrostis teff (Zucc.) Trotter) and three amaranth (Amaranthus caudatus L.) varieties from Ethiopia. The fat content ranged from 2.92 to $3.34 \%$ (averaging $3.06 \%$ ) and from 8.28 to $9.21 \%$ (averaging $8.6 \%$ ) for teff and amaranth, respectively. Linoleic, oleic and palmitic acid were predominant in both teff and amaranth, accounting for approximately 89 and $85 \%$ of total fatty acid content, respectively. The saturated to unsaturated fatty acids ratio ranged from 0.30 to 0.32 in teff and from 0.38 to 0.40 in amaranth. The parameters used to describe lipid quality, i.e., thrombogenicity and atherogenicity indices, show that teff was superior over amaranth, suggesting a preference for the former for healthy food formulation. The squalene content of white amaranth $(486.54 \mathrm{mg} / 100 \mathrm{~g} \mathrm{DM})$ was significantly higher than that of the other two varieties (327.54 and $340.81 \mathrm{mg} / 100 \mathrm{~g}$ DM for red and brown amaranth, respectively). In general, both gluten-free crops should be exploited for their potential as ingredients for the development of novel functional foods.

Keywords: Amaranthus caudatus L.; atherogenicity; Eragrostis teff (Zucc.) Trotter; fatty acid; squalene; thrombogenicity

\section{Introduction}

Teff (Eragrostis teff (Zucc.) Trotter) is a nutritious cereal indigenous to Ethiopia and Eritrea. According to the Ethiopian Central Statistical Agency report, teff represents the most important crop in terms of cultivation area and production quantity in the country. Approximately 3 million hectares are dedicated to the cultivation of teff, giving approximately 5.4 million tons of production with a yield of 17.56 quintals per hectare [1] As reported by Woldeyohannes et al. [2], the high adaptability of teff allows its cultivation in very different environmental conditions, characterized by high and low production input, impacting its composition.

Teff is widely used for making injera (a fermented traditional bread considered a staple food), a sweet unleavened bread called Kitta and a porridge by either mixing with other cereals such as wheat, maize, rice and barley, or alone [3]. However, teff has been underutilized for decades due to the lack of adequate knowledge on its nutritional and health benefits. Recently, having discovered the absence of gluten in teff, this crop is grabbing the attention of researchers and food processing industries for the formulation of foods, particularly for celiac patients [4,5]. The cultivation has therefore recently expanding to several other countries such as South Africa, the Netherlands and the United States [6]. 
Besides, consumer awareness of the health benefits of whole grains has led to a growing demand for healthier cereal $[7,8]$.

Considering the nutritional characteristics, teff contains more than $70 \%$ carbohydrate, 9-13\% protein, $2-3 \%$ fat, $2.0-3.5 \%$ fiber and $2.7-3.0 \%$ ash [9]. The mineral content, especially of iron, calcium and magnesium, is also higher than that of most common cereals including millet, rice and oat [10].

On the other hand, amaranth is an underutilized crop that has recently gained popularity due to its numerous agronomic and nutritional properties. It is recognized as a drought-resistant crop and is hence suitable for different environmental and climatic conditions [11]. From the nutritional point of view, amaranth contains fat (7.5\%), carbohydrate $(60-68 \%)$, ash $(2.5-3.1 \%)$ and a high protein content $(14.0-15.5 \%)$ in comparison to staple cereals such as wheat, maize and sorghum. According to Bojórquez-Veláquez et al. [12] and Amare et al. [13], a wide variability in fiber content was observed for different amaranth varieties, that could suggest the need for selection procedures to find the most promising varieties.

Moreover, amaranth shows a balanced amino acid profile and fulfils the requirements of the human diet for the majority of the essential amino acids [14]. Like teff, amaranth is also a gluten-free pseudo-cereal that can potentially be used as ingredient for gluten-free formulations [15]. Amaranth grain may be processed in various forms, such as popped, toasted, cooked, flaked, extruded and grinded into flour to be mixed with other flours for making bread, pasta, injera, porridge and instant drink with improved nutritional and technological qualities [13]. Previous studies on both teff and amaranth demonstrated the occurrence of variability in physicochemical properties among known varieties, which influence product nutritional value and technological applications [3,13].

There is a growing interest in the lipid fraction of flours, which can affect the health status and the oxidative stability of derived processed food. Moreover, the search for bioactive compounds such as squalene with multiple bio-functionality (antioxidant, antitumor, etc.) in underutilized plants is gaining attention in the global cosmetic industry [16]. The present paper assessed the variability in fatty acids profile, crude fat and squalene content and lipid quality of seven varieties of teff (Eragrostis teff (Zucc.) Trotter) and three varieties of amaranth (Amaranthus caudatus L.) grown in Ethiopia, and it represents, to the authors' knowledge, a comprehensive report of the nutritional characteristics of these flours, in view of their use in the formulation of novel functional foods.

\section{Materials and Methods}

\subsection{Sample Collection and Preparation}

Seven varieties of teff (Eragrostis tef (Zucc.) Trotter) grains, namely DZ-01-1278, DZ-011681, DZ-01-2053, DZ-01-2423, DZ-01-2675, DZ-01-99 and DZ-Cr-387 were collected from the storage bank of Debre Zeit Agricultural Research Center, Ethiopia, which were grown under the experimental field conditions of the research institute for teff breeding. Teff grains were sieved to remove immature seeds, straw and soil. Three varieties of amaranth grains, white, red and brown, were collected from the Bench Majji Zone, Ethiopia, which were grown under the farmer's field with no fertilizer application. Both teff and amaranth grains were collected from the 2015 harvest. Grains were milled and the flours were stored at $4{ }^{\circ} \mathrm{C}$ in polyethylene bags for further analyses. The main characteristics of the teff and amaranth varieties used in this study are presented in Table 1. 
Table 1. Description of teff and amaranth varieties used in the study $[17,18]$.

\begin{tabular}{|c|c|c|c|c|c|}
\hline Name of Varieties & Year of Release & Source & Seed Color & Local Name & $\begin{array}{c}\text { Adaptation Zone } \\
\text { (Altitude) } \\
\text { (masl) }\end{array}$ \\
\hline DZ-01-99 & 1970 & Debrezeit & Brown & Asgori & $1600-2400$ \\
\hline DZ-01-2423 & 2005 & Adet & Brown & Dima & $2000-2600$ \\
\hline DZ-01-2053 & $1999 / 8$ & Holetta & Brown & Holeta Key & 1900-2700 \\
\hline DZ-01-1278 & 2000 & Holetta & White & Ambo Toke & $2200-2400$ \\
\hline DZ-01-1681 & 2002 & Debrezeit & Brown & Key Tena & $1600-1900$ \\
\hline DZ-01-2675 & 2005 & Debrezeit & White & Dega Tef & $1800-2500$ \\
\hline DZ-Cr-387 & 2006 & Debrezeit & Very white & Quncho & $1800-2400$ \\
\hline White amaranth & - & Bench Majji & White & Katila & - \\
\hline Brown amaranth & - & Bench Majji & Brown & Katila & - \\
\hline Red amaranth & - & Bench Majji & Pale red & Katila & - \\
\hline
\end{tabular}

\subsection{Determination of Dry Matter}

Dry matter content was determined using AOAC (2000) method number 925.05 [19].

\subsection{Extraction of Fat}

Crude fat extraction was done using the accelerated solvent extractor (ASE). Briefly, a sample ( $3 \mathrm{~g})$ was accurately weighed and transferred to a $10 \mathrm{~mL}$ cell with $1.2 \mathrm{~g}$ of hydromatrics (diatomaceous earth). The extraction condition was the same used in Dionex application note 325 .

\subsection{Analysis of Fatty Acid Profile}

Fatty acid profile was determined using the method described by Jenkins [20] with modifications. Briefly, $40 \mathrm{mg}$ of lipid extract was transferred into a Pyrex tube. One milliliter of sodium methoxide in methanol $(0.5 \mathrm{M})$ and $1 \mathrm{~mL}$ of $0.6 \mathrm{mg} / \mathrm{mL}$ internal standard, C13:1 in n-heptane, were added to the Pyrex tube containing the lipid extract and incubated at $50{ }^{\circ} \mathrm{C}$ for $15 \mathrm{~min}$. The mixture was cooled at room temperature for $5 \mathrm{~min}$. To this mixture, $1.5 \mathrm{~mL}$ of $5 \% \mathrm{HCl}$ in methanol was added then incubated at $80{ }^{\circ} \mathrm{C}$ for $15 \mathrm{~min}$, followed by cooling at room temperature for $7 \mathrm{~min}$. To the cooled mixture, $2.5 \mathrm{~mL}$ of $6 \% \mathrm{~K}_{2} \mathrm{CO}_{3}$ and $1 \mathrm{~mL}$ of $\mathrm{n}$-heptane were added, vortex-mixed for $30 \mathrm{~s}$ and centrifuged at $4000 \times \mathrm{g}$ at $4{ }^{\circ} \mathrm{C}$ for $5 \mathrm{~min}$. The upper phase containing fatty acid methyl ester was injected into a gas chromatograph (Agilent 7890 gas chromatograph) equipped with an Agilent CFT modulator for GCxGC analysis, flame-ionization detector and Agilent 7693 autosampler. The gas chromatographic conditions were as follows: initial oven temperature $45^{\circ} \mathrm{C}$, isotherm (hold time) $2.0 \mathrm{~min}$, heating rate $50{ }^{\circ} \mathrm{C} / \mathrm{min}$ up to $170{ }^{\circ} \mathrm{C}$, isotherm (hold time) $25 \mathrm{~min}$, temperature increase by $2{ }^{\circ} \mathrm{C} / \mathrm{min}$ up to $240{ }^{\circ} \mathrm{C}$, isotherm (hold time) $16 \mathrm{~min}$, injection port temperature $270{ }^{\circ} \mathrm{C}$ and detector port temperature $250{ }^{\circ} \mathrm{C}$. The injected volume was $1 \mu \mathrm{L}$ in a split mode (160:1). Hydrogen was used as carrier gas. As the primary column, a Supelco SP-2560 $(75 \mathrm{~m} \times 0.18 \mathrm{~mm} \times 0.14 \mu \mathrm{m}$ film thickness $)$ with an initial flow rate of $0.25 \mathrm{~mL} / \mathrm{min}$, which was increased to $0.4 \mathrm{~mL} / \mathrm{min}$ at a rate of $0.002 \mathrm{~mL} / \mathrm{min}$, was used and as the secondary column, an Agilent J\&W HP-5ms $(3.8 \mathrm{~m} \times 0.25 \mathrm{~mm} \times$ $0.25 \mu \mathrm{m}$ film thickness) with an initial flow rate of $22 \mathrm{~mL} / \mathrm{min}$, increased to $35 \mathrm{~mL} / \mathrm{min}$ at a rate of $0.18 \mathrm{~mL} / \mathrm{min}$, was adopted. The valves were set to a modulation delay of $1 \mathrm{~min}$, a modulation period of $2.9 \mathrm{~s}$ and a sampling time of $2.77 \mathrm{~s}$. One microliter sample was injected in the pulsed split mode at a pressure of $25 \mathrm{psi}$ for $0.3 \mathrm{~min}$ and a split ratio of 160:1. The split-splitless inlet was run at a temperature of $270{ }^{\circ} \mathrm{C}$. The resulting two-dimensional chromatograms were analyzed with comprehensive GCxGC software (GC Image R 2.2 
GCXGC: Zoex Corp., Houston, TX, USA). The fatty acid composition was expressed using the formula described below.

Total fatty acids $(\mathrm{mg} / \mathrm{g}$ of sample $)=\frac{\left(V_{T P}-V_{I S}\right) * \mathrm{mg} \text { of internal standard }}{\left(V_{I S} * \text { sample weight }(\mathrm{g})\right)}$

where $V_{T P}$ is the volume of total peaks and $V_{I S}$ is the volume of internal standard.

\subsection{Determination of Squalene}

Squalene content in oils extracted from teff and amaranth grains was determined using high-performance liquid chromatography (HPLC) as described in He et al. [21].

\subsection{Lipid Quality Indices}

The quality of lipid was determined using the atherogenicity (AI) and thrombogenicity (TI) indices, calculated according to the formulas described below [22].

$$
\begin{gathered}
\mathrm{AI}=\frac{\mathrm{C} 12: 0+4 * \mathrm{C} 14: 0+\mathrm{C} 16: 0}{\Sigma \mathrm{MUFA}+\Sigma \operatorname{PUFA}(\mathrm{n}-6)+\Sigma \operatorname{PUFA}(\mathrm{n}-3)} \\
\mathrm{TI}=\frac{\mathrm{C} 14: 0+\mathrm{C} 16: 0+\mathrm{C} 18: 0}{0.5 * \Sigma \mathrm{MUFA}+0.5 * \Sigma \operatorname{PUFA}(\mathrm{n}-6)+3 * \Sigma \operatorname{PUFA}(\mathrm{n}-3)+\frac{\Sigma \operatorname{PPFA}(\mathrm{n}-3)}{\Sigma \operatorname{PUFA}(\mathrm{n}-6)}}
\end{gathered}
$$

\subsection{Statistical Analysis}

All analyses were done in triplicate and results were reported using the mean $\pm \mathrm{SD}$. One-way analysis of variance (ANOVA) was used to determine the presence of significant differences among the varieties, using the statistical package for the social sciences (SPSS) version 25. Mean separation was done using the Duncan multiple range test and significant differences were declared at $p<0.05$.

\section{Results and Discussion}

\subsection{Dry Matter, Total Fat and Fatty Acid Profile of Teff Varieties}

The dry matter and crude fat content, and fatty acid profiles of teff varieties are presented in Table 2. The dry matter content of teff samples ranged between 89.00 and $90.38 \mathrm{~g} / 100 \mathrm{~g}$, where the content in DZ-Cr-387 was significantly lower $(p<0.05)$ than the other teff varieties. The crude fat content was in the range from 2.92 to $3.34 \mathrm{~g} / 100 \mathrm{~g} \mathrm{DM}$, which was slightly higher than the content in barley, maize and wheat, but lower than that reported in sorghum and oat $[23,24]$. The result is consistent with the value detected by Agza et al. [25] but lower than that reported by Collar and Angioloni [26]. The fat content in DZ-Cr-387 (3.34 g/100 g DM) was significantly higher $(p<0.05)$ than the other teff varieties. On the other hand, the total fatty acid content of this variety was significantly higher $(p<0.05)$ than that found in DZ-01-1278, DZ-01-1681, DZ-01-2053 and DZ-01-2675 varieties. More than 25 fatty acids were identified in the studied teff varieties. However, the most abundant fatty acids were linoleic (C18:2, cis, cis-9,12), oleic (C18:1 cis 9), palmitic (C16:0), $\alpha$-linolenic (C18:3, all cis-9,12,15) and stearic (C18:0) in decreasing order (Table 2). 
Table 2. Fatty acid profile of different teff varieties (\% of the total fatty acid) *

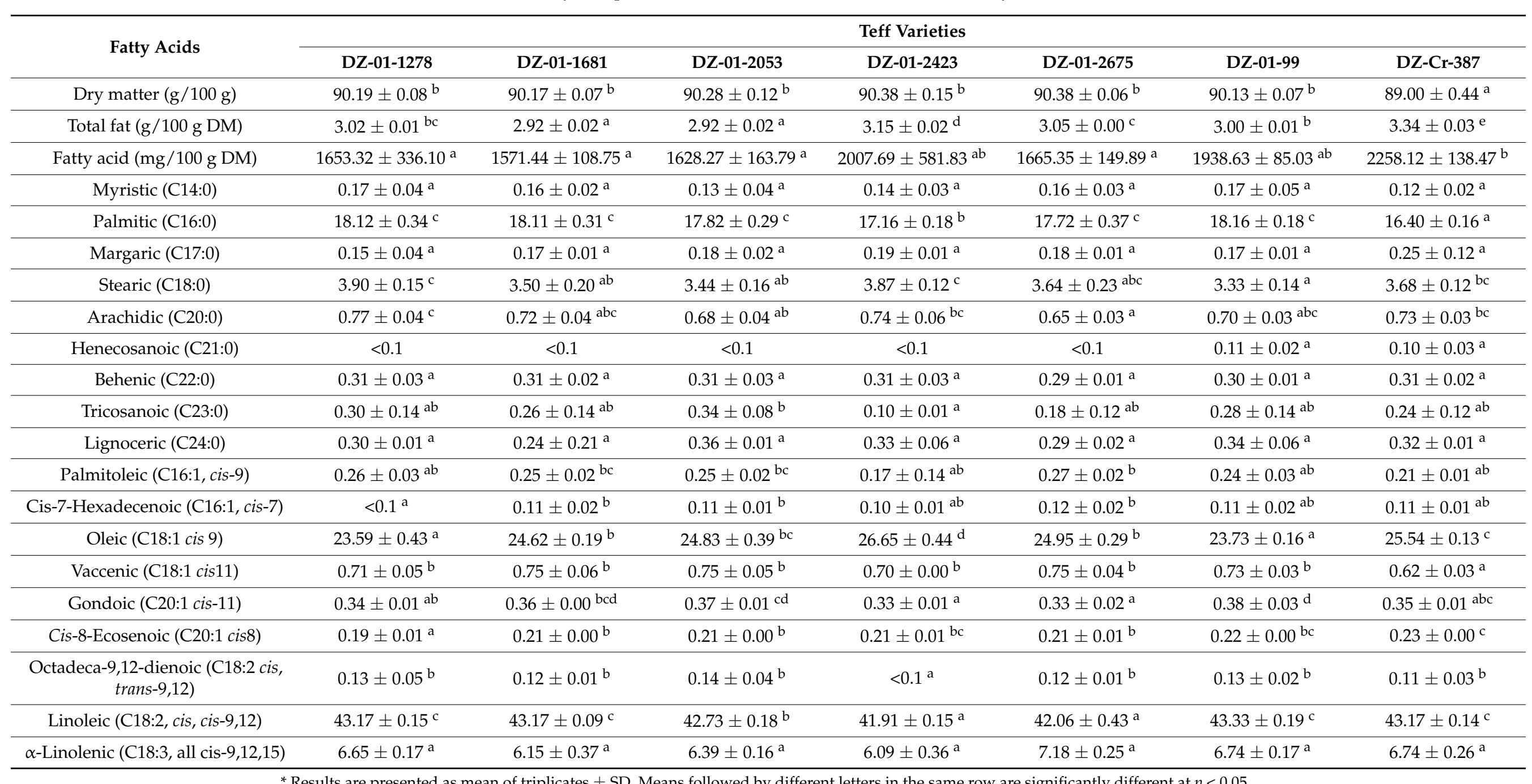

${ }^{*}$ Results are presented as mean of triplicates \pm SD. Means followed by different letters in the same row are significantly different at $p<0.05$. 
The content of palmitic acid (C16:0) in DZ-Cr-387 and oleic acid (C18:1 cis 9) in DZ-01-1278 and DZ-01-99 were significantly lower $(p<0.05)$ than that obtained in other teff varieties. DZ-01-2423 variety had higher oleic acid (C18:1 cis 9) content whereas both DZ-01-2423 and DZ-01-2675 varieties had lower linoleic acid (C18:2, cis, cis-9,12) content compared to the remaining teff varieties at $p<0.05$. All teff varieties did not reveal significant differences $(p>0.05)$ in omega 3 fatty acid ( $\alpha$-linolenic acid (C18:3, all cis-9,12,15)) content. The content of linoleic acid in the studied teff varieties was lower than that reported for barley and wheat but comparable with that reported for sorghum and oat. On the other hand, teff had higher $\alpha$-linolenic acid content than barley, sorghum, millet, wheat, rice, maize and oat $[23,24,27]$. Alpha linoleic acid, which is an omega 3 fatty acid, is a precursor for the higher $n-3$ polyunsaturated fatty acids (PUFAs) (eicosapentaenoic acid, docosapentaenoic and docosahexanoic acid). Thus, the presence of higher $\alpha$-linolenic acid in staple foods will protect consumers from the risk of cardiovascular disease, atherosclerosis and hypertension [28].

Table 3 shows the proportion of fatty acid groups, along with the atherogenic and thrombogenic indices of teff varieties. The total saturated fatty acid level ranged from 22.35 to $24.33 \%$; the lowest was obtained in DZ-Cr-387 variety and the highest in DZ-01-1278. Total unsaturated fatty acids ranged from 75.45 to $76.83 \%$, but no statistical difference among the varieties was found, and approximately two-thirds of total unsaturated fatty acids were PUFAs. The lowest percentage of PUFAs was found in DZ-Cr-387 and the highest was found in DZ-01-2423. The presence of a high proportion of PUFAs in oils is a desirable attribute for application in healthy food product development [29].

Table 3. Proportions of fatty acid groups (\% of total fatty acids) and thrombogenicity and atherogenicity indices of teff varieties.

\begin{tabular}{|c|c|c|c|c|c|c|c|}
\hline \multirow{2}{*}{ Fatty Acids } & \multicolumn{7}{|c|}{ Teff Varieties } \\
\hline & DZ-01-1278 & DZ-01-1681 & DZ-01-2053 & DZ-01-2423 & DZ-01-2675 & DZ-01-99 & DZ-Cr-387 \\
\hline SFA & $24.33 \pm 0.26^{d}$ & $23.81 \pm 0.39^{c}$ & $23.61 \pm 0.16^{c}$ & $23.13 \pm 0.12^{b}$ & $23.45 \pm 0.31 \mathrm{bc}$ & $23.82 \pm 0.23^{c}$ & $22.35 \pm 0.19^{a}$ \\
\hline UFA & $75.62 \pm 0.25^{a}$ & $76.14 \pm 0.40^{\mathrm{a}}$ & $76.34 \pm 0.17^{\mathrm{a}}$ & $76.83 \pm 0.12^{\mathrm{a}}$ & $76.52 \pm 0.30^{\mathrm{a}}$ & $76.15 \pm 0.22^{a}$ & $75.45 \pm 3.90^{\mathrm{a}}$ \\
\hline MUFA & $25.40 \pm 0.48^{\mathrm{a}}$ & $26.49 \pm 0.17^{b}$ & $26.75 \pm 0.45^{b c}$ & $28.51 \pm 0.38^{d}$ & $26.89 \pm 0.37^{b c}$ & $25.70 \pm 0.04^{\mathrm{a}}$ & $27.32 \pm 0.10^{c}$ \\
\hline PUFA & $50.22 \pm 0.23^{a}$ & $49.65 \pm 0.28^{a}$ & $49.58 \pm 0.31^{\mathrm{a}}$ & $48.32 \pm 0.26^{\mathrm{a}}$ & $49.63 \pm 0.63^{a}$ & $50.46 \pm 0.19^{a}$ & $48.14 \pm 3.97^{\mathrm{a}}$ \\
\hline Omega 6/Omega 3 & $6.50 \pm 0.17^{b}$ & $7.04 \pm 0.43^{c}$ & $6.69 \pm 0.16^{b c}$ & $6.90 \pm 0.42^{b c}$ & $5.86 \pm 0.18^{\mathrm{a}}$ & $6.43 \pm 0.17^{b}$ & $6.42 \pm 0.22^{b}$ \\
\hline SFA/UFA & $0.32 \pm 0.00^{c}$ & $0.32 \pm 0.01^{\mathrm{cd}}$ & $0.31 \pm 0.00^{a b c}$ & $0.30 \pm 0.00^{\mathrm{ab}}$ & $0.31 \pm 0.01 \mathrm{abc}$ & $0.31 \pm 0.00^{\mathrm{cd}}$ & $0.33 \pm 0.02^{a}$ \\
\hline PUFA/SFA & $2.06 \pm 0.01^{\mathrm{a}}$ & $2.08 \pm 0.05^{\mathrm{a}}$ & $2.10 \pm 0.01^{\mathrm{a}}$ & $2.09 \pm 0.00^{a}$ & $2.12 \pm 0.05^{\mathrm{a}}$ & $2.12 \pm 0.03^{a}$ & $2.15 \pm 0.19^{a}$ \\
\hline TI & $0.41 \pm 0.01^{\mathrm{a}}$ & $0.41 \pm 0.01^{\mathrm{a}}$ & $0.40 \pm 0.01^{\mathrm{a}}$ & $0.39 \pm 0.01^{\mathrm{a}}$ & $0.38 \pm 0.01^{\mathrm{a}}$ & $0.39 \pm 0.00^{\mathrm{a}}$ & $0.43 \pm 0.12^{\mathrm{a}}$ \\
\hline $\mathrm{AI}$ & $0.25 \pm 0.01^{\mathrm{c}}$ & $0.25 \pm 0.01^{c}$ & $0.24 \pm 0.01^{b c}$ & $0.23 \pm 0.00^{\mathrm{ab}}$ & $0.24 \pm 0.01^{b c}$ & $0.25 \pm 0.00^{c}$ & $0.23 \pm 0.01^{\mathrm{a}}$ \\
\hline
\end{tabular}

Results are presented as mean of triplicates \pm SD. Means followed by different letters in the same row are significantly different at $p<0.05$. SFA—saturated fatty acid, UFA — unsaturated fatty acid, MUFA—mono-unsaturated fatty acid, PUFA-polyunsaturated fatty acid, TI—-thrombogenicity index, AI—atherogenicity index.

The ratio of omega 6 to omega 3 fatty acids was in the range of 5.86 to 7.04 ; the highest was for DZ-01-2675 and the lowest was for DZ-01-1681. The result was lower than that reported for other cereals such as oat, barley, wheat, sorghum, rice and buckwheat ( 14-39), which is beneficial, taking into consideration the optimal recommendation of the Mediterranean diet (1-2:1) $[23,24,30]$ to reduce cardiovascular diseases. However, according to the European Food Safety Authority opinion, there is no strict recommendation, but it was advised that the intake of n- 6 and n-3 should be 4 and $0.5 \%$, respectively, of the total dietary energy [31].

The thrombogenicity index (TI) and atherogenicity index (AI) of teff were in the range from 0.38 to 0.41 and 0.23 to 0.25 , respectively (Table 3). The TI of teff was higher than quinoa (0.20), sunflower oil (0.20), rapeseed (0.10), peanut, sesame and olive (0.33-0.34) and oat (0.03-0.34), but lower than rice bran (0.49), buckwheat (0.52), Amaranthus hypochondriacus and Amaranthus cruentus (0.65-0.71), palm oil (1.92) and coconut oil (3.98). On the other hand, the AI of teff was higher than that of sunflower (0.08) and slightly higher than oat (0.17-0.19), but lower than Amaranthus hypochondriacus (0.31), palm oil (0.97) and coconut oil $(14.71)$ [30,32]. The low TI and AI values of teff compared to the oils of some cereals 
and oilseeds enable the crop to be considered as a healthy alternative for nutraceutical food development.

\subsection{Total Fat and Fatty Acid Profile of Amaranth Varieties}

Table 4 presents the dry matter and total fat content, and fatty acid profile of amaranth. The dry matter content was in the range of 88.83 and $89.23 \mathrm{~g} / 100 \mathrm{~g}$ for brown and white amaranth, respectively. The crude fat content of white amaranth $(9.14 \mathrm{mg} / 100 \mathrm{~g} \mathrm{DM})$ was significantly higher $(p<0.05)$ than that of the other two varieties, which was $8.44 \mathrm{mg} / 100 \mathrm{~g}$ $\mathrm{DM}$ and $8.28 \mathrm{mg} / 100 \mathrm{~g} \mathrm{DM}$, for brown and red amaranth, respectively. The result shows that the fat content of amaranth was higher than that found in other pseudocereals such as teff $(2.57 \mathrm{~g} / 100 \mathrm{~g})$, quinoa $(6.30 \mathrm{~g} / 100 \mathrm{~g})$ [25], buckwheat $(2.7 \mathrm{~g} / 100 \mathrm{~g})$ [24], millet (3.38-6.49 g/100 g) [33] and Amaranthus caudatus from the Spanish market (5.81 g/100 g) [26]. Total fatty acid content ranged between 5409 and $6111 \mathrm{mg} / 100 \mathrm{~g}$ DM; however, there was no statistically significant difference $(p>0.05)$ among the varieties considered. The major fatty acids measured in amaranth, in decreasing order, were linoleic (C18:2, cis, cis-9,12), oleic (C18:1 cis 9), palmitic (C16:0), stearic (C18:0) and vaccenic (C18:1 cis 11) (Table 4).

The content of linoleic acid in red amaranth $(46.39 \%)$ was approximately $10 \%$ higher than that found in white $(35.73 \%)$ and brown $(36.55 \%)$ amaranth varieties. The content in the former variety was comparable with that found in teff varieties (Table 2), higher than that reported for oat (34.6-38.2\%) [30] but lower than that reported for foxtail millets $(\sim 67 \%)$ [33]. The increased level of linoleic acid in red amaranth is compensated for by a decrease in oleic acid by approximately $10 \%$ compared to the other varieties (Table 4 ). Linoleic acid is a precursor for the higher omega 6 fatty acid called arachidonic acid within the body. Hence, the presence of a reasonable amount of linoleic acid in the diet minimizes the risk of cardiovascular disease (CVD) [34].

The content of vaccenic acid in amaranth ranged between 1.20 and $1.44 \%$; red amaranth had significantly higher $(p<0.05)$ levels than brown and white amaranth. The content of stearic (C18:0) acid was also significantly lower $(p<0.05)$ for red amaranth $(2.43 \%)$ with respect to white $(3.50 \%)$ and brown $(3.27 \%)$ varieties. The content in the latter varieties was comparable to that found in the teff varieties considered in the present study (Table 1). The content of stearic acid in amaranth varieties (2.43-3.5\%) was by far higher than that reported in other pseudocereals such as buckwheat $(2.00 \%)$ and quinoa $(0.59 \%)$ [24] but lower than that reported in millet (5.45-8.24\%) [33].

The content of palmitic acid (C16:0) in amaranth was in the range of 20.81 to $21.09 \%$ with no statistical difference among the varieties at $p>0.05$. However, the result was higher than that found in teff (16.40-18.16\%) (Table 2), millet (6.65-7.86\%) [33], quinoa $(9.18 \%)$ [24] and maize (12.61-16.22\%) [27], but it was comparable with that reported in buckwheat (19.96\%) [24] and oat (21.4-22.8\%) [30]. The content of omega 3 fatty acid was less than $1 \%$ in all amaranth varieties. This finding is in accordance with data reported by León-Camacho et al. [35].

Table 5 shows the proportion of fatty acid groups and the atherogenic and thrombogenic indices of amaranth varieties. The total saturated fatty acid content for red amaranth $(27.74 \%)$ was significantly lower than that of brown amaranth $(28.52 \%)(p<0.05)$, while there was no statistical difference between the contents of unsaturated fatty acid for all amaranth varieties. Moreover, the content of MUFA was lower in red (24.71\%) than in white $(35.16 \%)$ and brown $(34.16 \%)$ amaranth. On the contrary, the content of PUFA was higher for red amaranth $(47.48 \%)$ with respect to white $(36.47 \%)$ and brown $(37.30 \%)$ amaranth, but it was lower compared to that found in teff (48.11-50.22\%) (Table 3). The presence of a lower content of PUFAs in amaranth, compared to teff, can improve the oxidative and shelf stability of amaranth flour compared to teff flour. 
Table 4. Fatty acid profile of different varieties of Amaranthus caudatus grain (\% of the total fatty acid) *

\begin{tabular}{|c|c|c|c|}
\hline \multirow{2}{*}{ Fatty Acids } & \multicolumn{3}{|c|}{ Amaranth Varieties } \\
\hline & White & Brown & Red \\
\hline Dry matter & $89.23 \pm 0.07^{b}$ & $88.83 \pm 0.11^{\mathrm{a}}$ & $88.87 \pm 0.14^{\mathrm{a}}$ \\
\hline Total fat (g/100 g DM) & $9.14 \pm 0.07^{b}$ & $8.44 \pm 0.19^{a}$ & $8.28 \pm 0.07^{\mathrm{a}}$ \\
\hline Fatty acid (mg/100 g DM) & $6110.69 \pm 785.92^{\mathrm{a}}$ & $5738.18 \pm 682.36^{\mathrm{a}}$ & $5409.38 \pm 433.79^{a}$ \\
\hline Myristic (C14:0) & $0.25 \pm 0.03^{a}$ & $0.25 \pm 0.03^{\mathrm{a}}$ & $0.37 \pm 0.02^{b}$ \\
\hline Palmitic (C16:0) & $21.04 \pm 0.23^{\mathrm{a}}$ & $21.09 \pm 0.15^{\mathrm{a}}$ & $20.81 \pm 0.35^{\mathrm{a}}$ \\
\hline Anteiso-hexadecanoic (C17:0 anteiso) & $0.34 \pm 0.03^{a b}$ & $0.41 \pm 0.04^{\mathrm{b}}$ & $0.31 \pm 0.02^{\mathrm{a}}$ \\
\hline Margaric (C17:0) & $0.15 \pm 0.00^{b}$ & $0.15 \pm 0.02^{a b}$ & $0.13 \pm 0.01^{\mathrm{a}}$ \\
\hline Iso-heptadecanoic (C18:0 iso) & $0.78 \pm 0.03^{\mathrm{a}}$ & $0.84 \pm 0.01^{\mathrm{b}}$ & $0.98 \pm 0.01^{\mathrm{c}}$ \\
\hline Stearic (C18:0) & $3.50 \pm 0.17^{\mathrm{b}}$ & $3.27 \pm 0.10^{b}$ & $2.43 \pm 0.23^{a}$ \\
\hline Antesiso-octadecanoic (C19:0 anteiso) & $0.13 \pm 0.10^{\mathrm{a}}$ & $0.20 \pm 0.01^{\mathrm{a}}$ & $0.17 \pm 0.02^{\mathrm{a}}$ \\
\hline Iso-nonadecanoic (C20:0 iso) & $0.17 \pm 0.17^{a}$ & $0.28 \pm 0.05^{\mathrm{ab}}$ & $0.45 \pm 0.03^{b}$ \\
\hline Arachidic (C20:0) & $0.77 \pm 0.08^{a}$ & $0.77 \pm 0.03^{a}$ & $0.73 \pm 0.03^{a}$ \\
\hline Anteiso-eicosanoic (C21:0 anteiso & $<0.1^{\mathrm{a}}$ & $<0.1^{\mathrm{a}}$ & $0.11 \pm 0.02^{\mathrm{a}}$ \\
\hline Iso-heneicosanoic (C22:0 iso) & $<0.1^{\mathrm{a}}$ & $<0.1^{\mathrm{a}}$ & $0.11 \pm 0.01^{b}$ \\
\hline Behenic (C22:0) & $0.33 \pm 0.05^{\mathrm{a}}$ & $0.33 \pm 0.04^{\mathrm{a}}$ & $0.33 \pm 0.03^{a}$ \\
\hline Tricosanoic (C23:0) & $<0.1^{\text {a }}$ & $0.20 \pm 0.11^{\mathrm{a}}$ & $0.15 \pm 0.13^{a}$ \\
\hline Lignoceric (C24:0) & $0.35 \pm 0.05^{\mathrm{a}}$ & $0.35 \pm 0.05^{\mathrm{a}}$ & $0.37 \pm 0.06^{\mathrm{a}}$ \\
\hline Palmitoleic (C16:1, cis-9) & $0.23 \pm 0.03^{a}$ & $0.23 \pm 0.02^{\mathrm{a}}$ & $0.23 \pm 0.01^{\mathrm{a}}$ \\
\hline Cis-10-heptadecenoic (C17:1, cis-10) & $0.10 \pm 0.01^{\mathrm{a}}$ & $<0.1^{\mathrm{a}}$ & $<0.1^{\mathrm{a}}$ \\
\hline Oleic (C18:1 cis 9) & $32.91 \pm 1.05^{c}$ & $31.57 \pm 0.45^{b}$ & $22.10 \pm 0.18^{a}$ \\
\hline Vaccenic (C18:1 cis 11) & $1.20 \pm 0.02^{\mathrm{a}}$ & $1.20 \pm 0.05^{\mathrm{a}}$ & $1.44 \pm 0.02^{\mathrm{b}}$ \\
\hline Cis-16-octadecenoic (C18:1 cis 16$)$ & $0.13 \pm 0.21^{\mathrm{a}}$ & $<0.1^{\mathrm{a}}$ & $<0.1^{\mathrm{a}}$ \\
\hline Iso-octadecenoic (C18:1 iso) & $<0.1^{\mathrm{a}}$ & $0.15 \pm 0.01^{a b}$ & $0.17 \pm 0.01^{b}$ \\
\hline Anteiso-nonadecenoic (C19:1 anteiso) & $0.22 \pm 0.19^{\mathrm{a}}$ & $0.04 \pm 0.02^{\mathrm{a}}$ & $0.25 \pm 0.01^{\mathrm{a}}$ \\
\hline Cis-8-ecoseinoic (C20:1 cis 8) & $<0.1^{\mathrm{a}}$ & $0.10 \pm 0.17^{\mathrm{a}}$ & $<0.1^{\mathrm{a}}$ \\
\hline Gondoic $(\mathrm{C} 20: 1$ cis 11$)$ & $0.31 \pm 0.01^{\mathrm{a}}$ & $0.21 \pm 0.18^{\mathrm{a}}$ & $0.26 \pm 0.02^{\mathrm{a}}$ \\
\hline Cis, trans-9,12-octadecadienoic acid (C18:2 cis, trans-9,12) & $0.11 \pm 0.03^{\mathrm{a}}$ & $0.10 \pm 0.02^{a}$ & $<0.1^{\mathrm{a}}$ \\
\hline Linoleic (C18:2 cis, cis-9,12) & $35.73 \pm 1.00^{\mathrm{a}}$ & $36.55 \pm 0.64^{a}$ & $46.39 \pm 0.10^{b}$ \\
\hline$\alpha$-Linolenic $(\mathrm{C} 18: 3$, all cis-9,12,15) & $0.35 \pm 0.32^{\mathrm{a}}$ & $0.57 \pm 0.05^{\mathrm{ab}}$ & $0.85 \pm 0.10^{b}$ \\
\hline
\end{tabular}

${ }^{*}$ Results are presented as mean of triplicates \pm SD. Means followed by different letters in the same row are significantly different at $p<0.05$.

The omega 6 to omega 3 ratio was in the range of 54.90 to 68.63 ; the highest value was obtained for white amaranth, followed by brown amaranth. The ratio was much higher than that reported for most cereals, such as barley, oat, rice, sorghum and wheat [23], maize, rye, buckwheat and quinoa [24] which had an $\mathrm{n} 6$ to $\mathrm{n} 3$ ratio in the range of 6.0 to 32.7 . Brown and red amaranth had a comparable $n 6$ to $n 3$ ratio with millet [24]. The PUFA:SFA ratio of amaranth was relatively higher than that of teff, especially the white and brown amaranth varieties, which fell under the recommended range (1.0-1.5) for a diet helping to reduce cardiovascular disease [36].

The thrombogenicity index (TI) of amaranth was between 0.65 to 0.70 (Table 5), and the lowest and highest values were obtained for the red and white variety, respectively. The atherogenicity index (AI) of amaranth was the same for all varieties (0.31). The TI 
values of amaranth varieties were in accordance with those reported by Dubois et al. [32] for Amaranthus hypocondriacus and Amaranthus cruentus (0.65-0.71), but higher than that obtained for teff in the present study (Table 3), quinoa (0.2), oats (0.30-0.34) and buckwheat $(0.52)[30,32]$. On the other hand, the AI values of amaranth varieties were in agreement with those reported by Dubois et al. [32] for Amaranthus cruentus (0.31), higher than oats (0.17-0.19) and sunflower (0.08), but lower than palm (0.97) and coconut oil $(14.71)[30,32]$.

Table 5. Proportions of fatty acid groups (\% of total fatty acids) and thrombogenicity and atherogenicity indices of amaranth.

\begin{tabular}{cccc}
\hline \multirow{2}{*}{ Fatty Acids } & \multicolumn{3}{c}{ Amaranth Varieties } \\
\cline { 2 - 4 } & White & Brown & Red \\
\hline SFA & $28.16 \pm 0.34^{\mathrm{ab}}$ & $28.52 \pm 0.09^{\mathrm{b}}$ & $27.74 \pm 0.17^{\mathrm{a}}$ \\
UFA & $71.64 \pm 0.66^{\mathrm{a}}$ & $71.46 \pm 0.10^{\mathrm{a}}$ & $72.20 \pm 0.17^{\mathrm{a}}$ \\
MUFA & $35.16 \pm 1.19^{\mathrm{b}}$ & $34.16 \pm 0.62^{\mathrm{b}}$ & $24.71 \pm 0.23^{\mathrm{a}}$ \\
PUFA & $36.47 \pm 1.04^{\mathrm{a}}$ & $37.30 \pm 0.67^{\mathrm{a}}$ & $47.48 \pm 0.20^{\mathrm{b}}$ \\
Omega 6/Omega 3 & $68.63 \pm 13.66^{\mathrm{a}}$ & $64.17 \pm 4.48^{\mathrm{a}}$ & $54.90 \pm 6.09^{\mathrm{a}}$ \\
SFA/UFA & $0.39 \pm 0.01^{\mathrm{ab}}$ & $0.40 \pm 0.00^{\mathrm{b}}$ & $0.38 \pm 0.00^{\mathrm{a}}$ \\
PUFA/SFA & $1.30 \pm 0.04^{\mathrm{a}}$ & $1.31 \pm 0.03^{\mathrm{a}}$ & $1.71 \pm 0.01^{\mathrm{b}}$ \\
TI & $0.70 \pm 0.03^{\mathrm{b}}$ & $0.69 \pm 0.00^{\mathrm{b}}$ & $0.65 \pm 0.01^{\mathrm{a}}$ \\
AI & $0.31 \pm 0.01^{\mathrm{a}}$ & $0.31 \pm 0.00^{\mathrm{a}}$ & $0.31 \pm 0.01^{\mathrm{a}}$ \\
\hline
\end{tabular}

Results are presented as mean of triplicates \pm SD. Means followed by different letters in the same row are significantly different at $p<0.05$. SFA—saturated fatty acid, UFA- unsaturated fatty acid, MUFA-monounsaturated fatty acid, PUFA— polyunsaturated fatty acid, TI—thrombogenicity index, AI—atherogenic index.

\subsection{Correlation Analysis}

Table 6 shows how the main fatty acids were correlated in both teff and amaranth varieties. Palmitic acid was significantly negatively correlated with stearic acid $(r=-0.443$, $p=0.044)$ and oleic acid $(r=-0.691, p=0.001)$ for teff. However, the correlation of palmitic acid with both stearic and oleic acids was positive, although it was not statistically significant for amaranth. Stearic acid was significantly positively correlated with oleic acid $(r=0.922, p=0.000)$ and negatively correlated with linoleic acid $(r=0.914, p=0.001)$ in amaranth. Oleic acid was significantly negatively correlated with linoleic acid at $p=0.001$ and $p=0.000$ for teff and amaranth, respectively. Alpha-linolenic acid was significantly correlated with oleic acid $(r=-0.753, p=0.019)$ and linoleic acid $(r=0.761, p=0.017)$ in amaranth. Hlinková et al. [37] reported a negative correlation between oleic and linoleic acid in amaranth. Similarly, in the present study, a higher negative correlation was obtained between oleic and linoleic acid in amaranth. On the other hand, the lowest positive correlation was obtained between stearic and $\alpha$-linolenic acid in teff. Pearson correlation analysis showed that teff and amaranth had different biosynthetic pathways for the synthesis of the major fatty acids, as the direction of the correlation was the opposite for the majority of fatty acid pairs where correlation was established.

\subsection{Squalene Content of Teff and Amaranth Varieties}

Table 7 presents the squalene oils content from teff and amaranth grains. The content obtained from white amaranth $(486.54 \mathrm{mg} / 100 \mathrm{~g} \mathrm{DM})$ was significantly higher than that found in brown and red amaranth (327.54-340.81 mg/100 $\mathrm{g} \mathrm{DM}$ ), and in teff varieties (0.85-2.33 mg/100 g DM). Bojórquez-Velázquez et al. [12] reported lower contents of squalene (197-335 mg/100 g) in cultivated Amaranthus hypochondriacus and Amaranthus cruentus. The results show that the squalene content in amaranth was higher than other pseudo-cereals, such as quinoa (58.4 mg/100 g DM) and buckwheat (1.9 mg/100 g DM), and most other cereals and legumes [24]. Squalene is a plant secondary metabolite and an intermediate product of cholesterol biosynthesis, which takes place in humans under the skin and inside the adipose tissue. Squalene has several health benefits, such as anticancer and hypocholesterolemic effects [38]. Hence, the high level of squalene determined in the 
studied amaranth varieties could encourage its exploitation in the functional food market and cosmetics industry.

Table 6. Pearson correlation among the major fatty acids in teff and amaranth.

\begin{tabular}{|c|c|c|c|c|c|c|}
\hline Samples & Fatty Acids & Palmitic & Stearic & Oleic & Linoleic & $\alpha$-Linolenic \\
\hline Teff & \multirow{2}{*}{ Palmitic } & \multirow{2}{*}{1} & & & & \\
\hline Amaranth & & & & & & \\
\hline Teff & \multirow{2}{*}{ Stearic } & $-0.443 *(0.044)$ & \multirow{2}{*}{1} & & & \\
\hline Amaranth & & $0.234(0.544)$ & & & & \\
\hline Teff & \multirow{2}{*}{ Oleic } & $-0.691 * *(0.001)$ & $0.333(0.140)$ & \multirow{2}{*}{1} & & \\
\hline Amaranth & & $0.529(0.143)$ & $0.922 * *(0.000)$ & & & \\
\hline Teff & \multirow{2}{*}{ Linoleic } & $0.220(0.338)$ & $-0.371(0.098)$ & $-0.675^{* *}(0.001)$ & \multirow{2}{*}{1} & \\
\hline Amaranth & & $-0.553(0.122)$ & $-0.914^{* *}(0.001)$ & $-0.998^{* *}(0.000)$ & & \\
\hline Teff & \multirow{2}{*}{$\alpha$-Linolenic } & $0.310(0.172)$ & $0.114(0.623)$ & $-0.271(0.234)$ & $-0.082(0.724)$ & \multirow{2}{*}{1} \\
\hline Amaranth & & $-0.611(0.081)$ & $-0.645(0.060)$ & $-0.753 *(0.019)$ & $0.761 *(0.017)$ & \\
\hline
\end{tabular}

${ }^{*}$ Correlation is significant at $0.05 .{ }^{* *}$ Correlation is significant at 0.01 .

Table 7. Squalene content of teff and amaranth varieties.

\begin{tabular}{cc}
\hline Sample & Squalene (mg/100 g DM) \\
\hline White Amaranth & $486.54 \pm 10.20^{\mathrm{c}}$ \\
Brown Amaranth & $340.81 \pm 12.86^{\mathrm{b}}$ \\
Red Amaranth & $327.54 \pm 16.92^{\mathrm{b}}$ \\
DZ-01-1278 & $\mathrm{ND}$ \\
DZ-01-1681 & $0.85 \pm 0.09^{\mathrm{a}}$ \\
DZ-01-2053 & $\mathrm{ND}$ \\
DZ-01-2423 & $\mathrm{ND}$ \\
DZ-01-2675 & $\mathrm{ND}$ \\
DZ-01-99 & $2.33 \pm 0.15^{\mathrm{a}}$ \\
DZ-Cr-387 & $\mathrm{ND}$
\end{tabular}

Results are presented as mean of triplicates \pm SD. Means followed by different letters down the column are significantly different at $p<0.05$. ND: not detected.

\section{Conclusions}

The study shows that the content of fat in amaranth was two-fold higher than that found in teff, which consequently affected the profile and the content of total fatty acid. The major fatty acids found in both teff and amaranth were linoleic, oleic and palmitic acids, in decreasing order, where the three acids account for 85 and $89 \%$ of the total fatty acid in teff and amaranth, respectively. Although amaranth showed high crude fat and fatty acid content, the total amount of omega 3 present was less than that detected in teff. Except for the red amaranth that presented comparable total percentages of linoleic acid, the percentage of essential fatty acids in amaranth was less than that of teff despite the larger quantity of oil and fatty acid. Amaranth is a very good source of squalene compared with teff. In general, the lipid profile of teff and amaranth varieties can contribute to human nutrition and health, particularly for people on a strict gluten-free diet. In brief, this paper expands the current knowledge of the nutritional value of these two crops, not only for opening new market perspectives for their production and consumption, but also for sharing data on the availability of nutritious food and on target ingredients for novel functional foods formulation. 
Author Contributions: Conceptualization, E.A., A.L., A.G. and V.C.; methodology, E.A., L.G., A.L. and A.G.; validation, E.A., A.L., A.G., L.G. and V.C.; formal analysis, E.A. and L.G.; investigation, E.A. and L.G.; resources, A.L., A.G. and V.C.; writing-original draft preparation, E.A.; writing-review and editing, A.L. and A.G.; supervision, A.L., A.G. and V.C. All authors have read and agreed to the published version of the manuscript.

Funding: This research received no external funding.

Institutional Review Board Statement: Not applicable.

Informed Consent Statement: Not applicable.

Data Availability Statement: Original data of the research can be provided to interested groups upon request.

Acknowledgments: Endale Amare is grateful to the Coimbra Group Scholarship Programme for Sub-Saharan Africa for sponsoring his stay at the University of Padova, Italy.

Conflicts of Interest: The authors declare no conflict of interest.

\section{References}

1. Central Statistical Authority. Report on Area and Production of Major Crops; Central Statistical Authority: Addis Ababa, Ethiopia, 2019; Volume 1.

2. Woldeyohannes, A.B.; Accotto, C.; Desta, E.A.; Kidane, Y.G.; Fadda, C.; Pè, M.E.; Dell'Acqua, M. Current and projected ecogeographic adaptation and phenotypic diversity of Ethiopian teff (Eragrostis teff) across its cultivation range. Agric. Ecosyst. Environ. 2020, 300, 107020. [CrossRef]

3. Bultosa, G. Physicochemical characteristics of grain and flour in 13 tef [Eragrostis tef (Zucc.) Trotter] grain varieties. J. Appl. Sci. Res. 2007, 3, 2042-2450.

4. Callejo, M.J.; Benavente, E.; Ezpeleta, J.I.; Laguna, M.J.; Carrillo, J.M.; Rodríguez-Quijano, M. Influence of teff variety and wheat flour strength on breadmaking properties of healthier teff-based breads. J. Cereal Sci. 2016, 68, 38-45. [CrossRef]

5. Zhu, F. Chemical composition and food uses of teff (Eragrostis tef). Food Chem. 2018, 239, 402-415. [CrossRef] [PubMed]

6. Bultosa, G. Traditional African Bread and the Physicochemical Properties of Unfermented Flatbreads. In Encyclopedia of Food Chemistry; Varelis, P., Melton, L., Shahidi, F., Eds.; Elsevier: Amsterdam, The Netherlands, 2019; Volume 1, pp. 66-80. [CrossRef]

7. Alaunyte, I.; Stojceska, V.; Plunkett, A.; Ainsworth, P.; Derbyshire, E. Improving the quality of nutrient-rich Teff (Eragrostis tef) breads by combination of enzymes in straight dough and sourdough breadmaking. J. Cereal Sci. 2012, 55, 22-30. [CrossRef]

8. Ruxton, C.; Derbyshire, E. The health benefits of whole grains and fibre. Nutr. Food Sci. 2014, 44, 492-519. [CrossRef]

9. Bultosa, G.; Taylor, J.R.N. Paste and gel properties and in vitro digestibility of tef [Eragrostis tef (Zucc.) Trotter] Starch. Starch Stärke 2004, 56, 20-28. [CrossRef]

10. Rybicka, I.; Gliszczyńska-Świgło, A. Minerals in grain gluten-free products. The content of calcium, potassium, magnesium, sodium, copper, iron, manganese, and zinc. J. Food Compos. Anal. 2017, 61-67. [CrossRef]

11. Gresta, F.; Guerrini, A.; Sacchetti, G.; Tacchini, M.; Sortino, O.; Ceravolo, G.; Onofri, A. Agronomic, chemical, and antioxidant characterization of grain amaranths grown in a Mediterranean environment. Crop Sci. 2017, 57, 2688-2698. [CrossRef]

12. Bojórquez-Velázquez, E.; Velarde-Salcedo, A.J.; De León-Rodríguez, A.; Jimenez-islas, H.; Pérez-Torres, J.L.; Herrera-Estrella, A.; Barba de la Rosa, A.P. Morphological, proximal composition, and bioactive compounds characterization of wild and cultivated amaranth (Amaranthus spp.) species. J. Cereal Sci. 2018, 83, 222-228. [CrossRef]

13. Amare, E.; Mouquet-Rivier, C.; Rochette, I.; Adish, A.; Haki, G.D. Effect of popping and fermentation on proximate composition, minerals and absorption inhibitors, and mineral bioavailability of Amaranthus caudatus grain cultivated in Ethiopia. J. Food Sci. Technol. 2016, 53, 2987-2994. [CrossRef]

14. Amare, E.; Mouquet-Rivier, C.; Servent, A.; Morel, G.; Adish, A.; Haki, G.D. Protein Quality of Amaranth Grains Cultivated in Ethiopia as Affected by Popping and Fermentation. Food Nutr. Sci. 2015, 6, 38-48. [CrossRef]

15. Thompson, T.; Dennis, M.; Higgins, L.A.; Lee, A.R.; Sharrett, M.K. Gluten-free diet survey: Are Americans with coeliac disease consuming recommended amounts of fibre, iron, calcium and grain foods? J. Hum. Nutr. Diet. 2005, 18, 163-169. [CrossRef]

16. Huang, Z.-R.; Lin, Y.-K.; Fang, J.-Y. Biological and Pharmacological Activities of Squalene and Related Compounds: Potential Uses in Cosmetic Dermatology. Molecules 2009, 14, 540-554. [CrossRef] [PubMed]

17. Assefa, K.; Yu, J.-K.; Zeid, M.; Belay, G.; Tefera, H.; Sorrells, M.E. Review Breeding tef [Eragrostis tef (Zucc.) trotter ]: Conventional and molecular approaches. Plant Breed. 2011, 130, 1-9. [CrossRef]

18. Merga, M. Achievements and Challenges of Tef Breeding in Ethiopia. J. Agr. Sci. Food Res. 2018, 9, $204-211$.

19. AOAC. Official Methods of Analysis; Association of Official Analytical Chemists: Washington, DC, USA, 2000.

20. Jenkins, T.C. Technical note: Common analytical errors yielding inaccurate results during analysis of fatty acids in feed and digesta samples. J. Dairy Sci. 2010, 93, 1170-1174. [CrossRef]

21. He, H.-P.; Cai, Y.; Sun, M.; Corke, H. Extraction and Purification of Squalene from Amaranthus Grain. J. Agric. Food Chem. 2002, 50, 368-372. [CrossRef] [PubMed] 
22. Ulbricht, T.; Southgate, D. Coronary heart disease: Seven dietary factors. Lancet 1991, 338, 985-992. [CrossRef]

23. Liu, K. Comparison of Lipid Content and Fatty Acid Composition and Their Distribution within Seeds of 5 Small Grain Species. J. Food Sci. 2011, 76, C334-C342. [CrossRef]

24. Ryan, E.; Galvin, K.; O'Connor, T.P.; Maguire, A.R. Phytosterol, Squalene, Tocopherol Content and Fatty Acid Profile of Selected Seeds, Grains, and Legumes. Plant Foods Hum. Nutr. 2007, 62, 85-91. [CrossRef]

25. Agza, B.; Bekele, R.; Shiferaw, L. Quinoa (Chenopodium quinoa, Wild.): As a potential ingredient of injera in Ethiopia. J. Cereal Sci. 2018, 82, 170-174. [CrossRef]

26. Collar, C.; Angioloni, A. Pseudocereals and teff in complex breadmaking matrices: Impact on lipid dynamics. J. Cereal Sci. 2014, 59, 145-154. [CrossRef]

27. Sanjeev, P.; Chaudhary, D.P.; Sreevastava, P.; Saha, S.; Rajenderan, A.; Sekhar, J.C.; Chikkappa, G.K. Comparison of fatty acid profile of specialty maize to normal maize. J. Am. Oil Chem. Soc. 2014, 91, 1001-1005. [CrossRef]

28. Wang, C.; Harris, W.S.; Chung, M.; Lichtenstein, A.H.; Balk, E.M.; Kupelnick, B.; Jordan, H.S.; Lau, J. n-3 Fatty Acids from Fish or Fish-Oil Supplements, but not Alpha-Linolenic Acid, Benefit Cardiovascular Disease Outcomes in Primary- and SecondaryPrevention Studies: A Systematic Review. Am. J. Clin. Nutr. 2006, 84, 517. [CrossRef]

29. Zaier, M.M.; Ciudad-Mulero, M.; Cámara, M.; Pereira, C.; Ferreira, I.C.F.R.; Achour, L.; Morales, P. Revalorization of Tunisian wild Amaranthaceae halophytes: Nutritional composition variation at two different phenotypes stages. J. Food Compos. Anal. 2020, 89, 103463. [CrossRef]

30. Kouřimská, L.; Sabolová, M.; Horčička, P.; Rys, S.; Božik, M. Lipid content, fatty acid profile, and nutritional value of new oat cultivars. J. Cereal Sci. 2018, 84, 44-48. [CrossRef]

31. EFSA. Scientific Opinion on Dietary Reference Values for fats, including saturated fatty acids, polyunsaturated fatty acids, monounsaturated fatty acids, trans fatty acids, and cholesterol. EFSA J. 2010, 8, 1-107.

32. Dubois, V.; Breton, S.; Linder, M.; Fanni, J.; Parmentier, M. Fatty acid profiles of 80 vegetable oils with regard to their nutritional potential. Eur. J. Lipid Sci. Technol. 2007, 109, 710-732. [CrossRef]

33. Zhang, A.; Liu, X.; Wang, G.; Wang, H.; Liu, J.; Zhao, W.; Zhang, Y. Crude fat content and fatty acid profile and their correlations in foxtail millet. Cereal Chem. 2015, 92, 455-459. [CrossRef]

34. Willett, W.C. The Role of Dietary n-6 Fatty Acids in the Prevention of Cardiovascular Disease. J. Cardiovasc. Med. 2007, 8 (Suppl. 1), S42-S45. [CrossRef] [PubMed]

35. León-Camacho, M.; García-González, D.L.; Aparicio, R. A detailed and comprehensive study of amaranth (Amaranthus cruentus L.) oil fatty profile. Eur. Food Res. Technol. 2001, 213, 349-355. [CrossRef]

36. Kang, M.J.; Shin, M.S.; Park, J.N.; Lee, S.S. The effects of polyunsaturated: Saturated fatty acids ratios and peroxidisability index values of dietary fats on serum lipid profiles and hepatic enzyme activities in rats. Br. J. Nutr. 2005, 94, 526-532. [CrossRef]

37. Hlinková, A.; Bednárová, A.; Havrlentová, M.; Šupová, J.; Čičová, I. Evaluation of fatty acid composition among selected amaranth grains grown in two consecutive years. Biology 2013, 68, 641-650. [CrossRef]

38. Tikekar, R.V.; Ludescher, R.D.; Karwe, M.V. Processing Stability of Squalene in Amaranth and Antioxidant Potential of Amaranth Extract. J. Agric. Food Chem. 2008, 56, 10675-10678. [CrossRef] 